\title{
Enfermedad meningocóccica: consultas recurrentes
}

\author{
José Cofré
}

\section{Meningococcal disease: Frequently asked questions}

On account of an increase of serogroup W135 meningococcal disease (M.D.) observed in Santiago, Chile, during last two years the medical community has experienced an avidity to update their knowledge about M.D. treatment and its prevention. In a queries and answers mode, the following topics on M.D. are presented: nasopharyngeal carriage and its importance, immunity and protection against the disease, reasons to choice ceftriaxone as the first line antibiotic in treatment, rationality and indications of chemoprophylaxis, fundamentals and advantages of conjugate vaccines, its indications, schedules, contraindications and decisions making in public health.

Key words: Meningococcal disease, Neisseria meningitidis, carriage, immunity, treatment, chemoprophylaxis, conjugate vaccines, public health.

Palabras clave: Enfermedad meningocóccica, Neisseria meningitidis, portación, inmunidad, tratamiento, quimioprofilaxis, vacunas conjugadas, salud pública.

\section{Justificación}

$\mathrm{D}$ esde el año 2010 se detectó la presencia de un nuevo serogrupo de Neisseria meningitidis en Chile: el serogrupo W135. Con anterioridad y, durante aproximadamente 20 años, predominaron los casos de enfermedad meningocóccica (E.M.) causadas por el serogrupo B, ante lo cual se descartó utilizar las vacunas existentes en ese momento en otras latitudes. Sin haber aumentado en forma significativa los casos globales de E.M. en el país, respecto a las décadas anteriores, la aparición de un serogrupo de $N$. meningitidis inmunoprevenible ha suscitado el interés y necesidad de la comunidad médica por informarse respecto al nuevo fenómeno epidemiológico y ha surgido una gran demanda de la ciudadanía por recibir las vacunas conjugadas antimeningocóccicas actualmente disponibles y licenciadas en el país. Para ahondar en la situación epidemiológica chilena actualizada acerca de la E.M., recomiendo a los lectores consultar las lecturas anotadas al final de esta publicación. Se abordan, a continuación aquellos aspectos que los colegas médicos deben resolver con mayor frecuencia, en respuesta a las necesidades de la comunidad.

\section{Portación de Neisseria meningitidis}

\section{¿Qué se sabe sobre la portación de Neisseria menigitidis?}

Neisseria meningitidis ("meningococo") convive frecuentemente con el ser humano; no existe reservorio animal ni inanimado de esta bacteria, es altamente lábil fuera de su ambiente natural: la nasofaringe humana.
Comúnmente, 5 a $10 \%$ de los adultos somos portadores faríngeos de N. meningitidis, condición que puede ser transitoria (pocos días o semanas), crónica (varios meses) o intermitente. Durante períodos de alza manifiesta de casos de E.M., la frecuencia de esta portación puede elevarse, alcanzando cifras de 20 a $40 \%$ o aún mayores; no obstante, no se sabe a cabalidad si esta mayor frecuencia actúa como reservorio o sólo es consecuencia del aumento de casos observado. Grupos de hospederos jóvenes, en convivencia estrecha, como son estudiantes en internados y contingentes militares, son quienes presentan la más altas tasas de portación. Interesante es precisar que la mayoría de los aislados de meningococo obtenidos de portadores, son acapsulados (no tipificables y dudosamente patógenos); incluso durante brotes epidémicos este hecho sigue siendo así.

\section{¿Qué trascendencia tiene el ser portador de la bacteria?}

Tiene consecuencias benéficas y potencialmente perjudiciales para el individuo. Beneficioso es experimentar momentáneamente la portación pues ella estimula la síntesis de anticuerpos bactericidas humorales ( $\operatorname{IgM}, \operatorname{IgG}$ ) y de mucosas (IgA) que a la larga, protegen al hospedero contra la infección. Se piensa que este es uno de los mecanismos que hace inmune al adulto, a diferencia de lo que sucede con la población infantil. A este fenómeno, se ha planteado como hipótesis, se sumaría el estímulo al sistema inmune dado por otras especies bacterianas con antigenicidad cruzada con $N$. meningitidis capsulada, por ejemplo: $N$. meningitidis no capsulada (avirulentas) o Neisseria lactamica, especie muy frecuente en la microbiota faríngea humana.
Hospital Luis Calvo Mackenna Santiago, Chile. Servicio de Pediatría. Unidad de Infectología.

Conflictos de interés: El autor ha recibido honorarios de SanofiPasteur como expositor en actividades científicas de la empresa y apoyo financiero para asistencia a eventos científicos internacionales. Igualmente, ha recibido financiamiento de Novartis para asistir a eventos científicos en el extranjero.

Recibido: 14 de noviembre de 2012

Correspondencia a:

José Cofré Guerra

pepecofre@gmail.com 
El perjuicio potencial de una portación es desarrollar la enfermedad, lo que sería más probable en personas sin esta capacidad bactericida específica del plasma, es decir, personas que han adquirido la bacteria tan sólo pocos días antes de enfermar o que presentan alteración de la inmunidad humoral, como esplenectomizados (anatómicos o funcionales), personas deficientes de complemento y otros. A ello se suman factores como una infección viral reciente -clásica es la relación entre influenza y alza de casos de E.M.-, infección por Mycoplasma pneumoniae y agentes irritantes de la vía aérea como el humo de cigarrillos.

El balance entre portación y desarrollo de inmunidad específica o de enfermedad no está del todo bien estudiado ni comprendido. Sí se sabe que, en general, quienes desarrollan una E.M. han adquirido la bacteria recientemente y no han sido portadores por un mayor lapso de tiempo.

¿Cuál es el riesgo de contagiarse con un portador?

La inmensa mayoría de los casos de E.M. no tienen una conexión epidemiológica con otro caso índice y aparecen como casos "sin contacto"; ello puede deberse, en parte a la rápida acción de efectuar quimioprofilaxis sobre los contactos pero, también a la baja contagiosidad de $N$. meningitidis y la necesidad de convivir estrechamente con la fuente contagiante. En ese sentido, la transmisión sería "eficiente" sólo si la persona susceptible se expone en forma muy cercana y sostenida en el tiempo, a las secreciones del portador (tos, bostezo, estornudo); esta dinámica existe en el hogar, en colegios, jardines infantiles y puede producirse en otras circunstancias como viajes prolongados en buses, aviones u otros (plazo que ha sido estimado en 4 a 8 horas) u otras situaciones de hacinamiento humano. Arbitrariamente se ha definido como contacto de un caso de E.M., en riesgo de enfermar, como "aquel que duerme bajo el mismo techo que el caso índice"y se hace extensiva esta condición a una semana antes de declararse la enfermedad en el caso índice, considerando que la incubación de la E.M., es, en cerca de $90 \%$ de los casos, inferior a 7 días. Los contactos en el hogar tienen tasas de ataque $400,500 \mathrm{y}$ hasta 1.000 veces mayores que la población general.

\section{¿Habría alguna indicación para estudiar portación} nasofaríngea de N. meningitidis?

Para el caso individual, ninguna, dada la gran dinámica del fenómeno ya descrita, la dificultad en predecir qué trascendencia clínica y epidemiológica podría tener el detectar un portador y, por último, la complejidad de aislar el meningococo en la secreción naso-faríngea y tipificarlo. Con el propósito de comprender mejor la epidemiología de la E.M., se diseñan periódicamente estudios en población general o grupos focalizados de individuos.
¿En qué radica la inmunidad anti-meningocóccica?

Descansa en factores inespecificos como la indemnidad de mucosas, fagocitosis (la que será fuertemente complementada por anticuerpos anti-meningocóccicos del tipo IgG) y el sistema del complemento, y factores especificos como la presencia de $\operatorname{IgA}$ secretoria e IgG en la mucosa faríngea e $\operatorname{IgG}$ plasmática con actividad bactericida dirigida contra la cápsula bacteriana, en concentraciones suficientes. En la práctica, se considera protegida una persona que tiene anticuerpos bactericidas plasmáticos en un título $\geq 1: 8$. Esta es la meta a alcanzar con la vacunación. Células de memoria del tipo LB son capaces de responder con una rápida síntesis de $\mathrm{IgG}$ específica al re-exponer el sistema inmune al contacto con la infección natural o a los antígenos de una re-vacunación.

\section{Manejo clínico de los pacientes}

\section{¿Qué tipo de precauciones deben aplicarse y por cuánto tiempo en un paciente con E.M. durante su hospitalización?}

Deben aplicarse precauciones por gotitas. El ingreso a una habitación individual es opcional pero recomendable, sin embargo, si esto no es posible, debe cumplirse la separación de camas a más de un metro.

Estas precauciones deben cumplirse por $24 \mathrm{~h}$ si el paciente es tratado con ceftriaxona. Un esquema de penicilinoterapia no asegura la erradicación faríngea de $N$. meningitidis, aun siendo una cepa sensible in vitro a penicilina $\mathrm{G}$.

\section{¿Por qué es recomendable efectuar el tratamiento de la E.M. con ceftriaxona?}

La primera razón es que en nuestro país se ha documentado en los últimos 10 años entre 60 y $80 \%$ de resistencia intermedia a penicilina en cepas de $N$. meningitidis estudiadas en el ISP (frecuencia de $49 \%$ para el año 2012), situación que pone en duda la esterilización del LCR en pacientes con compromiso meníngeo tratados con penicilina G. En segundo lugar está el ya anotado beneficio erradicador que tiene ceftriaxona sobre $N$. meningitidis de la mucosa nasofaríngea, en el plazo de 24 horas. Las dosis de ceftriaxona a emplear son: $100 \mathrm{mg} /$ $\mathrm{kg} /$ día en niños bajo 8 años y de 2 a 4 gramos diarios en niños mayores y adultos. Si se descartó el compromiso meníngeo, las otras localizaciones de la E.M. se pueden tratar con dosis pediátricas de $50 \mathrm{mg} / \mathrm{kg} /$ día y de 2 gramos diarios en adultos.

\section{Profillaxis de E.M. en los contactos}

\section{¿En quienes está indicada la profilaxis?}

- En quienes durmieron bajo el mismo techo que el caso índice, en la última semana. 
- En parejas sexuales de los casos índices, aun si no cumplen la condición anterior.

- En contactos cercanos en salas cunas, jardines infantiles, colegios, hogares de menores, recintos carcelarios y militares.

- En quienes han viajado más de cierto número de horas (4 a 8 hrs) con un caso índice en un mismo bus, tren o avión u otro medio de transporte.

- En quienes practican la reanimación cardiopulmonar de un caso clínico, sin protección de mascarilla, o reanimación con maniobras boca-boca o boca-tubo.

Es responsabilidad exclusiva de los equipos de epidemiología efectuar la qiuimioprofilaxis y establecer sus límites, es decir, a quienes corresponde aplicarla, en el hogar del caso índice y en las instituciones o lugares que éste hubiera frecuentado la semana anterior a enfermar. Los equipos tratantes deben colaborar efectuando la notificación telefónica de todo caso sospechoso de E.M., de inmediato, apenas se ha planteado el diagnóstico clínico y sin esperar la confirmación del laboratorio de microbiología.

\section{Vacunación anti-meningocóccica}

\section{En forma resumida, ¿qué beneficios otorga el recibir una vacuna conjugada anti-meningocóccica?}

Es un excelente inductor de anticuerpos específicos contra el (los) antígeno(s) contenido(s) en la vacuna. Una dosis (dos a cuatro dosis en el caso de lactantes) produce(n) una seroconversión en alrededor de $90 \%$ de los individuos vacunados, en títulos (concentraciones) considerados protectores, contra todos los antígenos contenidos en la vacuna. Además, disminuye en forma significativa (aproximadamente a 1/3), la tasa de portación de $N$. meningitidis en los vacunados, con respecto a no vacunados, beneficiando a quienes viven en su entorno (inmunidad de rebaño).

\section{¿Qué ventajas tienen las vacunas conjugadas contra N. meningitidis sobre las elaboradas con sólo polisacárido capsular?}

Se ha señalado que disminuyen la portación faríngea y con ello, otorgan protección a terceros no vacunados; son capaces además, de estimular la memoria inmune, $\mathrm{y}$, muy principalmente, permiten estimular la respuesta protectora en lactantes, ya desde los primeros meses de vida, propiedades todas que no tienen las vacunas polisacarídicas.

\section{¿En adultos, es necesario utilizar entonces, vacunas conjugadas más que polisacarídicas?}

No siendo "necesario" desechar las vacunas en base a polisacáridos, también en adultos es deseable emplear vacunas conjugadas por su efecto de rebaño y por la induc- ción de memoria inmune específica contra meningococo, cualidades ausentes en las polisacarídicas. En caso de no disponerse de vacunas conjugadas, puede indicarse vacunas polisacarídicas que contengan los antígenos adecuados a la situación epidemiológica (p. ej.: hoy en día en Chile, vacuna ACWY-PS).

\section{¿Por qué se recomienda vacunar sólo a lactantes, prescolares y, en oportunidades, a adolescentes y adultos jóvenes?}

La incidencia de E.M. es constantemente máxima en los primeros años de vida, aproximadamente hasta los 5 años de edad; hasta entonces, hemos ido adquiriendo paulatinamente inmunidad humoral específica, en forma silenciosa, pero una parte de los niños aún no la ha alcanzado y, la exposición cercana y sostenida a las secreciones respiratorias de un portador de meningococo puede traducirse con mayor probabilidad que en adultos en una enfermedad.

En adolescentes y adultos jóvenes, se concentra usualmente el segundo grupo etario afectado con mayor frecuencia; probablemente factores determinantes sean sus hábitos sociales de convivencia, la co-habitación en hogares estudiantiles, el besarse, la conducta de fumar, la asistencia discotecas y bares u otros determinantes no reconocidos. En la situación epidemiológica chilena, este grupo etario no representa, sin embargo, el segundo en frecuencia, quizás porque los mencionados factores son relativamente menos importantes que en otras latitudes; en Chile, el segundo grupo etario en frecuencia está en la edad escolar pre-adolescentes.

En adultos, en general, la incidencia de E.M. es muy menor por el fenómeno antes mencionado, de inmunización natural y específica contra $N$. meningitidis en el curso de los años.

\section{¿Algún otro grupo de personas debe vacunarse durante brotes epidémicos?}

- Sí, quienes laboran con cepas de N. meningitidis y muestras clínicas potencialmente positivas con esta bacteria.

- No sólo en períodos epidémicos sino siempre, debe ofrecerse vacunación a los pacientes con afecciones que favorecen un curso fatal de la E.M., esos son: pacientes asplénicos funcionales y quirúrgicos, pacientes con déficit de factores del Complemento, pacientes con infección por VIH en etapa de SIDA, particularmente niños.

- No está explícitamente recomendado pero un grupo con mayor exposición a los casos índices son las personas que laboran cuidando grupos numerosos de párvulos y lactantes no vacunados, es decir, en jardines infantiles/ salas cunas. Si los menores no hubieran sido vacunados, es aconsejable vacunar a estos grupos de adultos. 


\section{¿Por qué el esquema de vacunación en lactantes considera un mayor número de dosis que en niños sobre 2 años de edad?}

La inmadurez del sistema inmune en los primeros años de vida explica el siguiente hecho conocido: que un mismo antígeno induce mejor respuesta en términos de títulos y frecuencia de seroconversión mientras mayor es el niño. Por ejemplo: una dosis de vacuna conjugada anti-Haemophilus influenzae tipo b administrada a los 18 meses de vida induce tan buena respuesta en frecuencia y título de anticuerpos, como tres dosis administradas en el primer año de vida. Esta constante en la vacunación del lactante es más manifiesta en vacunas que contienen antígenos múltiples, es el caso de las vacunas anti-neumocóccicas y, ahora, las meningocóccicas tetravalentes. Ensayos de inmunogenicidad de las vacunas meningocóccicas conjugadas tetravalentes han determinado la necesidad de aplicar tres dosis en el primer año de vida (2-4 y 6 meses) + un refuerzo en el segundo año, para obtener seroconversión y títulos protectores contra los cuatro antígenos, en $90 \%$ o más de los lactantes vacunados. En forma comparativa, los esquemas de 9-12 meses de las vacunas Men ACWY-D (Menactra $\left.{ }^{\circledR}\right)$ y MenACWY$\mathrm{CRM}_{197}\left(\right.$ Menveo $\left.{ }^{\circledR}\right)$, otorgan un beneficio similar, con tan sólo dos dosis.

Tabla 1. Características de las dos vacunas conjugadas disponibles en el mercado internacional, a la fecha

\begin{tabular}{|c|c|c|}
\hline Nombre & MenACWY-D & MenACWY-CRM \\
\hline Nombre comercial & Menactra $\AA$ & Menveo ${ }^{\circ}$ \\
\hline Fabricante & SanofiPasteur & Novartis \\
\hline Origen & Francia, E.U.A. & Italia, Alemania \\
\hline Composición & $\begin{array}{l}\text { Polisacárido capsular } \\
\text { N. meningitidis A-C-W-Y } \\
4 \mu \mathrm{g} \mathrm{c/u}\end{array}$ & $\begin{array}{l}\text { Oligosacárido capsular } \\
\text { N. meningitidis A } 10 \mu \mathrm{g} \\
\text { C-W135-Y } 5 \mu \mathrm{g} \mathrm{c/u}\end{array}$ \\
\hline Carrier & $\begin{array}{l}\text { Toxoide diftérico } \\
10 \mu \mathrm{g}\end{array}$ & $\begin{array}{l}\text { Toxina diftérica modificada (Cross } \\
\left.\text { reacting material-CRM }{ }_{197}\right) 32 \text { a } 63 \mu \mathrm{g}\end{array}$ \\
\hline Presentación & 1 vial líquido $0,5 \mathrm{ml}$ & $\begin{array}{l}2 \text { viales: } \\
\text { - } \text { Men A liofilizado } \\
\text { - } \text { Men C-W-Y líquido 0,6 } \mathrm{ml}^{1}\end{array}$ \\
\hline Edad recomendada & 9 meses a 55 años & 2 a 55 años \\
\hline $\begin{array}{l}\text { Esquema de } \\
\text { aplicación }\end{array}$ & $\begin{array}{l}9 \mathrm{~m}<2 \text { años: } 2 \text { dosis IM espaciadas } \\
\text { por } 3 \text { meses }{ }^{2} \\
>2 \text { años: } 1 \text { dosis IM }\end{array}$ & 1 dosis IM $^{2}$ \\
\hline $\begin{array}{l}\text { Interacción con } \\
\text { otras vacunas }\end{array}$ & $\begin{array}{l}\text { Tresvírica y Prevenar7 } \AA \\
\text { Sin mayor interferencia }\end{array}$ & $\begin{array}{l}\text { Tresvírica y y antivaricela: sin interfe- } \\
\text { rencia. Prevenar } 7 \circledR \text { : información no } \\
\text { disponible }\end{array}$ \\
\hline $\begin{array}{l}\text { Duración de } \\
\text { inmunidad }\end{array}$ & Estimada en 3 años & Información no disponible \\
\hline
\end{tabular}

'Actúa como solvente del otro vial. en pacientes con patologías de riesgo (ver texto) se recomienda aplicar dos dosis espaciadas por dos meses.

\section{¿Afecta la vacunación con estos productos la respuesta a otras vacunas aplicadas en forma concomitante?}

Este aspecto ha sido evaluado parcialmente para ambas vacunas conjugadas.

Los ensayos con Menactra ${ }^{\circledR}$ y vacunación conjunta con vacuna Prevenar7® (datos no disponibles para Prevenar13® o Synflorix $\AA$ ) o con vacuna tresvírica (sarampión/ rubéola/parotiditis) permiten asegurar que, en general, la respuesta a todos estos antígenos es suficiente y protectora aunque se observó una menor respuesta que en el grupo control. A su vez, la respuesta a los serogrupos A-C-W135 e Y de $N$. meningitidis no se vio mayormente afectada.

Los ensayos con Menveo ${ }^{\circledR}$ han evaluado su aplicación conjunta con vacunas de pre-adolescentes/adolescentes (dTPa y vacuna contra VPH), estudios en que no se ha observado interferencia significativa. Información reciente permite asegurar su no interferencia con la vacuna tresvírica ni con vacuna contra la varicela, aplicadas a los 12 meses de edad. No obstante, a la fecha de preparar este manuscrito, MenACWY-CRM ${ }_{197}$ aún no ha sido aprobada para indicar bajo dos años de edad.

En opinión de este autor, el fenómeno de interferencia entre vacunas meningocóccicas conjugadas polivalentes y vacunas propias del Programa Nacional de Inmunizaciones (PNI) debe ser estudiado con mayor profundidad y resuelto para ambos productos. No obstante, en una situación de brotes epidémicos, el beneficio de administrar estas vacunas puede ser mayor que un grado de interferencia inmunológica con otras vacunas incluidas en el PNI.

\section{¿Existen limitaciones clínicas para indicar las vacunas anti-meningocóccicas disponibles en el mercado?}

De partida, y siendo rigurosos con las evaluaciones efectuadas a ambas vacunas antes de ser aprobadas para su uso clínico, formalmente debemos atenernos a las edades $\mathrm{y}$ condiciones en que estos productos han sido ensayados (Tabla 1). No disponemos de información sobre beneficios y/o efectos adversos en mujeres embarazadas, personas sobre 55 años de edad ni mujeres en lactancia. En pacientes inmunocomprometidos no hay contraindicación formal de estas vacunas, dado que su composición no contiene microrganismos vivos, sólo antígenos purificados $d e N$. meningitidis. No obstante, debe tenerse en consideración que en pacientes con deficiente inmunidad celular $\mathrm{y} / \mathrm{o}$ de anticuerpos, es posible que la respuesta formadora de anticuerpos sea inferior a la de la población sana.

En opinión de este autor, si la situación epidemiológica es crítica (valoración cargada de subjetividad) o la voluntad del solicitante o sus apoderados es firme respecto a recibir la vacuna, ella puede ser indicada cuidando advertirle sobre una posible menor eficacia que 
la esperada por ellos y de no garantizarse la inocuidad de la administración de la vacuna.

\section{¿Cuánto dura la inmunidad otorgada por las vacunas conjugadas anti-meningocóccicas?}

Siendo productos de reciente desarrollo, la experiencia en este punto es aún limitada. La vacunación de adolescentes, que ya lleva más años de aplicación (vacuna MenACWY-D), ha permitido comprobar que al cabo de 5 años se han reducido en forma significativa los títulos de anticuerpos inducidos por la vacunación primaria de ellos y un porcentaje de estos adolescentes disminuyó a niveles no protectores, aunque mantuvo memoria inmunológica adecuada; de esta manera, la revacunación de refuerzo, elevó nuevamente, y en forma rápida, los anticuerpos bactericidas a concentraciones que correlacionan con protección. En pacientes con patologías que entrañan riesgo de adquirir una E.M. que tenga un curso fatal se recomienda la revacunación luego de 3 a 5 años de la primovacunación, según si el esquema primario se aplicó antes o a partir de los 2 años de edad, respectivamente. Se estima (subrayado), que la vacunación del lactante sano debiera tener una duración similar a pacientes con patologías de riesgo y, por ende, debiera revacunarse a los 3 años de la primovacunación.

\section{¿Contienen thimerosal estas vacunas?}

No, ningún tipo de preservante ni adyuvantes

\section{¿Contraindicaciones?}

Para la vacuna MCV4-D (Menactra $\left.{ }^{\circledR}\right)$ señala el fabricante como contraindicación el antecedente de haber padecido un síndrome de Guillain Barré (SGB). Esta es una precaución extrema pues, si bien en un comienzo del uso clínico de la vacuna se observó en E.U.A. una mayor incidencia de SGB, ello no se confirmó cuando se generalizó el uso del producto.

Para la vacuna MenACWY-CRM (Menveo®) señala el fabricante la alergia al látex como única contraindicación, toda vez que el tapón de la jeringa contiene esta sustancia en una concentración de $10 \%$. Se recomienda no vacunar pacientes con antecedente de S. Guillain Barré.

\section{¿Intercambiabilidad de ambas vacunas?}

No hay información disponible. Al momento actual es recomendable que en personas que deban recibir dos dosis de vacuna, se administre ambas dosis con un producto del mismo fabricante.

\section{¿Qué condiciones epidemiológicas toman en consideración las autoridades sanitarias para emprender una campaña de vacunación?}

La decisión de vacunar es compleja y comprende consideraciones técnicas y políticas, estas segundas son ineludibles pues la E.M., siendo una afección contagiosa, con elevada letalidad (usualmente 10-20\%), y que no respeta edades, genera fuertes reacciones de pánico en la población y una rápida presión de los medios de comunicación sobre las autoridades de salud.

Consideraciones técnicas. La aparición de algunos o todos los siguientes elementos de juicio son decidores para adoptar una conducta activa:

- Incremento significativo en el número de casos sobre el histórico en una región o nación.

- Aparición de un nuevo serogrupo ausente en los años previos y su incremento paulatino.

- Concentración de una mayoría de los casos en un mismo serogrupo.

- Distribución geográfica de los casos reiteradamente en una misma localidad/comuna o distrito.

- Velocidad de progresión del genio epidémico.

Algunos de estos criterios son subjetivos. Quizás por ello, el CDC de Atlanta, Georgia, definió, de acuerdo al comportamiento histórico de la E.M. para los Estados Unidos de América, tres criterios objetivos, en el año 1997, para combatir la E.M. causada por $N$. meningitidis del serogrupo C:

- La aparición de 3 casos en un plazo $\leq$ tres meses, en una misma localidad o distrito

- Los casos residen en el misma área pero no tienen contacto cercano entre sí

- Tasas superiores a 10 casos por 100.000 habitantes

Comentario de este autor es que esos criterios del CDC fueron definidos según la realidad poblacional americana y la epidemiología de la E.M. en E.U.A. en los años previos, para su aplicación interna y en E.M. causada por el serogrupo $\mathrm{C}$, no constituyendo criterios rígidos que debieran cumplirse para tomar decisiones en otras latitudes cuyas realidades poblacionales y comportamiento de la bacteria circulante pudieran ser enteramente diferentes.

Consideraciones políticas. Las autoridades pertinentes toman en consideración además estos otros factores para decidir una vacunación en campaña:

- La opiniones de expertos en vacunaciones.

- La disponibilidad del recurso económico.

- La mortalidad observada en el genio epidémico.

- El impacto en la opinión pública de la situación epidemiológica reinante en la E.M.

- La presión ejercida por la comunidad y actores políticos no gubernamentales.

- El tratamiento del tema efectuado por los medios de comunicación.

- La existencia de otros problemas de salud pública en ese momento y, en definitiva, sus prioridades en salud

- El momento político interno en cada país. 


\section{Resumen}

A raíz de un alza en la frecuencia de casos de enfermedad meningocóccica (E.M.) del grupo W135 en la ciudad de Santiago, Chile, observada durante 2011 y 2012, se ha producido una avidez en la comunidad médica por actualizar su información acerca de los recursos recomendados para combatirla y prevenirla. En una modalidad de preguntas y respuestas, se abordan los siguientes tópicos en enfermedad meningocóccica: portación nasofaríngea y su trascendencia, inmunidad y protección contra la enfermedad, razones para preferir ceftriaxona en el tratamiento de la afección, racionalidad e indicaciones de la quimioprofilaxis, fundamentos y ventajas de las vacunas conjugadas, indicaciones, esquemas, contraindicaciones y toma de decisiones en salud pública.

\section{Lecturas recomendadas}

1.- Departamento de Epidemiología Minsal. Informe de resultados de vigilancia de laboratorio. Enfermedad invasora Neisseria meningitidis. 2011-2012. Noviembre 6, 2012 (Semana 44). http://epi.minsal.cl/vigilanciaepidemiologica/enfermedades-de-notificacionobligatoria/enfermedad-meningococica/

2.- Broome C V. The carrier state: Neisseria meningitidis. J Antimicrobial Chemother 1986; 18 (Suppl A): S25-S34.

3.- Gorringe A R. Can Neisseria lactamica antigens provide an effective vaccine to prevent meningococcal disease? Expert Rev Vaccines 2005; 4 (3): 373-9.

4.- Departamento de Epidemiología. Ministerio de Salud. Situación epidemiológica de la enfermedad meningocócica. (Información disponible al 5 de octubre 2012, semana 40).

5.- Departamento de Epidemiología. Ministerio de Salud. Situación enfermedad meningocócica por serogrupo W-135. Semana Epidemiológica 1 a 45. (desde el 01/01/2012 al 10/11/2012). Información al 13 de noviembre 2012. http://epi. minsal.cl/epi/html/bolets/reportes/Meningitis/ EM_SE_452012.pdf

6.- Informe Regional de SIREVA II 2010. Datos por país y por grupos de edad sobre las características de los aislamientos de Streptococcus pneumoniae, Haemophilus influenzae y Neisseria meningitidis, en procesos invasores. Chile, págs: 84-102.

7.- Documentos técnicos. Tecnologías Esenciales de Salud. Informe Regional de SIREVA II. Datos por país y por grupos de edad sobre las característicasde los aislamientos de Streptococcus pneumoniae, Haemophilus influenzae y Neisseria meningitidis, en procesos invasores. 2000-2005. Chile, págs: 94-114.

8.- Vigilancia de Laboratorio de enfermedad invasora Neisseria meningitidis. Laboratorio de Referencia 2006-2011. Boletín Instituto de Salud Pública de Chile 2012; 2 (2): 1-18.

9.- Menactra $^{\mathrm{TM}}$. SanofiPasteur (Data on File, pages 1-9). Antecedentes presentados a la FDA, E.U.A. para solicitar la licencia del producto.

10.- Menveo $^{\mathrm{TM}}$. Novartis. (Data on File, pages 1-15). Antecedentes presentados al Instituto de Salud Pública de Chile para solicitar la licencia del producto.

11.- Anonymous. Control and Prevention of Serogroup C Meningococcal Disease: Evaluation and Management of Suspected Outbreaks: Recommendations of the Advisory Committee on Immunization Practices (ACIP). MMWR Morb Mortal Wkly Rep 1997; RR 46 (5): 13-21.
12.- Prevention and Control of Meningococcal Disease. Recommendations of the Advisory Committee on Immunization Practices. MMWR Morb Mortal Wkly Rep 2005; 54; RR 7: 1-17.

13.- Updated recommendations for use of meningococcal conjugate vaccines -Advisory Committee on Immunization Practices (ACIP), 2010. Centers for Disease Control and Prevention (CDC). MMWR Morb Mortal Wkly Rep 2011; 60 (3): 72-6.

14.- Meningococcal vaccines: WHO position paper, November 2011. Wkly Epidemiol Rec 18 november 2011, 86th year / 18 novembre 2011, 86e année. No. 47, 2011, 86: 521-40. http:// www.who.int/wer

15.- Pina L M, Bassily E, Machmer A, Hou V, Reinhardt A. Safety and immunogenicity of a quadrivalent meningococcal polysaccharide diphtheria toxoid conjugate vaccine in infants and toddlers: three multicenter phase III studies. Pediatr Infect Dis J 2012; 31: 1173-83.

15.- Klein N P, Reisinger K S, Johnston W, Odrljin T, Gill C J, Bedell L, Dull P. Safety and immunogenicity of a novel quadrivalent meningococcal CRM-conjugate vaccine given concomitantly with routine vaccinations in infants. Pediatr Infect Dis J 2012; 31 (1): 64-71. doi: 10.1097/ INF.0b013e31823dce5c. 